\title{
What CLASS are you in? A study of social class, school choice and identity
}

\author{
Kevin Cahill
}

School of Education, UCC

We do not go to bed in single pairs; even if we choose not to refer to them, we still drag there with us the cultural impedimenta of our social class, our parents lives, our bank balances, our sexual and emotional expectations, our whole biographies / all the bits and pieces of our unique existences." (Angela Carter, The Magic Toyshop)

\section{Welcome to my world}

My $\mathrm{PhD}$ investigates schools and communities as places constructed by ideas of social class, school choice, identity and comparisons between people as worthy and unworthy, deserving and undeserving. This thesis contributes to the social justice genre of social science research where equal educational opportunities are seen as an essential ingredient in a just society. I explore the tension between what may be termed here, for the purposes of clarity, the middle-class and the working-class in the context of an Irish urban second level school with DEIS status. DEIS stands for Delivering Equality of Opportunity in Schools and it is the designation given to schools where a significant proportion of students are from working-class backgrounds. One adult participant in this study informed me that "social class didn't exist in Ireland, that it was an English thing". You may make your own mind up but not before you ask some important questions:

Does everybody get the same opportunities to be educated?

Does school choice contribute to the creation of middle-class and working-class schools?

Do we make assumptions about people because of the school they attend(ed)?

How are our identities formed in terms of social class, positioning and schooling?

My $\mathrm{PhD}$ questions the social, cultural and political world of school choice and student identity. Issues of social class, inequality, stratification and identity frame the life-world of the study. I examine how the schools that we go to and the choices that are (un)available to us are intrinsically linked to issues of social class and contribute to our performance of identity.

At the core of this research is a zeal for transformative action in terms of the provision of equality of opportunity in educational settings. The intention is to open up critical 
spaces where we can ask questions regarding equality and social class in an Irish education context.

\section{Researching people and culture}

Ethnography is a research field concerned with researching people and culture. My research is essentially a study of the social, cultural and political spaces of our school experiences and the complex (and classed) identities that are formed out of our constant interactions with people, place and space.

This ethnography undertook an in-depth analysis of one school community as a case study of school choice and identity formation. The school community is understood to be the inside world of the school and the outside world of the community and society. The people within and about this community create the interactions and moments of identity construction in a lived and living way.

This research provided a forum for the voices of those marginalised (knowingly and unknowingly) through classed positioning. I also hope that the opening up of discussion around the area of school choice, identity, privilege and difference will prove transformative for participants from marginalised places. It may open up realisations of inequality and inspire those on the margins to take control of their futures.

\section{The methods of cultural exploration}

This study strives for an inside view of life-worlds through participation, observation and interview. This ethnography involved semi-structured interviews with thirty second level students, ten parents and ten teachers from the chosen research setting of Portown Community School. These interviews generated the data along with hundreds of hours of researcher participation and observation in the school and the community.

As this research develops, it also becomes clear that the macro-world of policy, legislation and societal structures has a significant influence on the world of the school and the microworld of the person. Therefore, this study focuses on telling the stories of students from a marginalised community, with unequal opportunities, who are often wrongly dismissed as incapable or undeserving. I also focus on how the world of the individual is inextricably wound and bound by the political and social landscapes of our world. 


\section{Findings}

The data in this study has been generated over a two-year period and the following key themes are emerging as significant.

Authentic and mystified worlds: The study reveals that there is a significant chasm between people's lived experience of working-class spaces and the mystified views of them as dangerous, violent and undeserving places. Many of the participants recalled stories of where mention of their place and school immediately created a distance between themselves and others. For instance, one student recalled how "when they ask you where you're from and you say Portown they think you're a scumbag and then they go 'what school do you go to?' And you say Portown then they think you're slow." Such instances are moments of what Beverley Skeggs describes as inscription, where another assumes a position of superiority, morally and intellectually, because of place and social class. These mystified worlds were often displaced by authentic world experiences where students presented powerful moments of resistance and success in the face of adverse positioning.

Unwriting social class: There is a body of research heralding the "death of class" as a mode of social interrogation. This study contends that social class is definitely not dead but it may well have been bound in invisible cloth in an attempt to erase its uncomfortable appearance in contemporary political discussion. This study includes a critical analysis of legislation and educational policy documents that relate to equality as an issue in education and finds that social class has indeed been erased or omitted from many of them. It may have found suitably sanitised terms in "disadvantage", "social exclusion", "social inclusion" and "socio-economic status" that often serve to de-script social class from politics and society. This is important; in order to negotiate equality of opportunity and equality of condition for people, it is important that foundational issues such as social class inequality are recognised. For some people, that which is not written ceases to exist. Social class may be an uncomfortable topic for some people to address, but it is also a very necessary one.

Class differences and the myth of equal opportunities: This theme embodies the public delusion that we are all individuals who are given the same opportunities in life and that it is almost entirely our own fault when we fail to succeed. The data reveals powerful misconceptions regarding the nature of our lived world and that the same opportunities are not available to everyone. The data suggests that we are not all treated equally, that schools, families, people and places do afford and constrain educational opportunity. My interactions with participants around the topic of school choice were particularly constructive in this regard. As analysis progresses, it is emerging that students from working-class spaces do not have the same choices and opportunities as their middle-class counterparts, and that any discussion of equality needs to be tempered by the reality of the life-world of students from working-class backgrounds. 
Persisting and resisting inscriptions: Many participants in this study showed critical selfawareness of how they were and are being positioned by social class and the inscriptions of others, and others did not. However, all people are constantly undertaking a process of self-authoring where issues such as social class and the positions imposed by self and others are significant. Therefore, on a psychosocial level, this study delves into the nuanced world of how others see us and how we see ourselves. Social class and relational positioning emerge as central spaces of self-authoring. Social class features on every level of the identity work being performed by participants. It is enmeshed throughout all of us in conscious and subconscious ways. Many of the participants resist negative inscriptions and consciously produce themselves as successful and ambitious role models for their communities; others disengage from their life-worlds and re-figure themselves.

Denials of place: Some participants in this study were locked in a denial of place and space. One such participant, who has lived fifteen of his seventeen years in Portown felt that none of the names or associations of the place applied to him as he had been born in another town about thirty miles away. This is a denial, an act of re-figuring the self. This identity work points to actions where participants decouple themselves from the social class baggage of family, peers, school and community. Therefore, some participants tended to speak of themselves as different, "not from here", and as outsiders. Such actions function to position self and others in a relational field that often does nothing more than reproduce stereotypical inscriptions and create further difficulties for those being positioned as the working-class other. The idea of escape figures prominently in the data. It contributes to notions of a deficit culture; where the working-class are not considered equal in educational terms because of what they lack. This idea of deficit often ignores the effect of society, positioning and wealth on people's educational opportunities. Such instances narrate the working-class school and place as badges of shame that need to be hidden and eradicated from one's social identity. Such actions may inscribe the individual as socially mobile and yet they also create this disruptive notion of deficit where the culture being left behind is unfairly labelled as flawed and devalued.

\section{Conclusion}

The themes that are outlined above are only partly representative of the breadth and depth of the data in this study. Let it suffice to say that the worlds of identity and social class enmeshed within education, society and the community unearth powerful messages about our place in the world and the interlocking and situated nature of experience and action. From a national policy point of view we may consider examining the make-up of our schools and communities in order to develop more equitable structures for our young people. Our curricula may need to be revisited in terms of their cultural relevance to various groupings in our society. Our national policies should carry the weight of their discursive 
convictions and actively work towards, not against, equality of educational opportunity.

We are all complicit actors in our world and the responsibility for fostering equality lies with each of us as an individual and in our socially and politically negotiated actions. Privilege is real. Inequality is real. Act. Speak. Write. Level the playing field. Opportunity is for everyone.

Kevin Cahill is a third year PhD student under the supervision of Professor Kathy Hall. Thank you to my supportive supervisor and also to her colleagues on the Cohort PhD in Education team. 